\title{
The rationale for B lymphocyte depletion in Graves' disease. Monoclonal anti-CD20 antibody therapy as a novel treatment option
}

\author{
Daniel El Fassi ${ }^{1,3}$, Claus H Nielsen ${ }^{3}$, Hans C Hasselbalch ${ }^{2}$ and Laszlo Hegedüs ${ }^{1}$ \\ Departments of ${ }^{1}$ Endocrinology and Metabolism and ${ }^{2}$ Hematology, Odense University Hospital, 5000, Odense C, Denmark and ${ }^{3}$ Institute for \\ Inflammation Research, Rigshospitalet National University Hospital, Copenhagen, Denmark \\ (Correspondence should be addressed to D El Fassi; Email: fassi@dadlnet.dk)
}

\begin{abstract}
We have reviewed the immunology of thyroid autoimmunity with special reference to the importance of B lymphocytes (B cells) in thyroidal and extrathyroidal Graves' disease (GD), thus providing a framework for the hypothesis that B cell depletion may be beneficial in GD. Additionally, after reviewing the efficacy and safety in other autoimmune diseases, we propose that treatment with the B celldepleting agent Rituximab may become a clinically relevant treatment option in selected cases of GD, particularly when complicated with thyroid-associated ophthalmopathy.
\end{abstract}

European Journal of Endocrinology $154623-632$

\section{Introduction}

Graves' disease (GD) is a frequent autoimmune disease with a prevalence around $1-2 \%$ (1). The efficacy of antithyroid drug therapy is unsatisfactory since only around half of the patients achieve remission after 12-18 months of treatment (2). Radioiodine and thyroid surgery are the definitive treatment options (2), but many patients decline these treatments, in part because of the risk of permanent hypothyroidism. Thyroid-associated ophthalmopathy (TAO) is a serious feature, present in some degree in half the patients, which often requires immunosuppressive treatment and sometimes retrobulbar irradiation or surgical orbital decompression $(1,3)$. The hyperthyroidism of GD is a classical autoantibody-dependent autoimmune disorder, while the pathogenesis of the extrathyroidal manifestations is more complicated. Chronic autoimmune thyroiditis (Hashimoto's thyroiditis, HT), is characterized by hypothyroidism due to a destructive lymphocytic infiltration of the thyroid. At present, the only treatment of HT is life-long substitution with thyroid hormone and remission is extremely rare (4). B cells are involved in the pathogenesis of autoimmune diseases at several levels, even in diseases generally viewed as $\mathrm{T}$ cell mediated. In addition to being precursors for antibody-secreting plasma cells, B cells are also efficient antigen-presenting cells (APC) in autoimmune disease, as shown in animal models of diabetes (5), rheumatoid arthritis (RA) (6) and systemic lupus erythematosus (SLE) $(7,8)$. In murine models of autoimmune thyroid disease (AITD), B cells are shown to act as APCs $(9,10)$ and are a prerequisite for the initiation of the disease process (11). Recently, Pichurin et al. (12) have demonstrated the importance of B cells on $\mathrm{T}$ cell activation in GD.

Rituximab (RTX), a monoclonal antibody directed against the B cell surface antigen CD20, is a B celldepleting agent, primarily used in the treatment of $B$ cell non-Hodgkin's lymphomas $(13,14)$. Theoretically, a temporary depletion of $\mathrm{B}$ cells may be beneficial, or indeed curative, in autoantibody-associated diseases by disruption of a vicious circle of self-perpetuating auto-reactive B cells (15). Preliminary reports of beneficial effects of RTX in various autoimmune diseases make it relevant to speculate about the potential effect of B cell depletion in AITD (16).

\section{Autoimmune thyroid disease}

GD is characterized by hyperthyroidism and most often a diffuse goitre due to a non-destructive hypertrophy and hyperplasia of the thyroid (1). About half the patients have varying degrees of clinically detectable TAO, and more rarely dermopathy is present (1). Both genetic and environmental factors are involved in the pathogenesis (17-20). A simplistic model for the 
pathogenesis of GD is a defect in regulatory T cells causing expansion of T-helper cells which, through cytokine production, induce $\mathrm{B}$ cells to differentiate into plasma cells (21). Plasma cells produce the pathogenetic thyrotrophin receptor antibodies (TRabs), first identified in 1956 (22), which are responsible for the clinical syndrome of hyperthyroidism.

The hyperthyroidism of GD is considered a classic autoantibody-dependent autoimmune disease, since it can be transferred across the placenta from mother to child and by transfer of plasma $(1,23,24)$. In contrast, the pathogenesis of the extrathyroidal manifestations of GD is less well characterized. In TAO and thyroid dermopathy, autoantibodies, ectopic expression of thyroid-associated antigens (TAs), systemic low grade inflammation as well as local disturbances in fibroblast function, accumulation of hyaluronan and glycosaminoglycans and mechanical factors are involved in the disease pathogenesis and propagation (24-26). HT, with its lymphocytic infiltration of the thyroid, is considered $\mathrm{T}$ cell driven. The destructive aspects of HT are caused by T cell-mediated cytotoxicity and induction of apoptosis (27).

As described below, a clear distinction between B celland $\mathrm{T}$ cell-mediated diseases is probably too simplistic. In AITD, various cellular interactions between B cells, $\mathrm{T}$ cells and other immune cells, such as natural killer (NK) cells and dendritic cells (DC), exist (28-30). Even thyroidal follicular cells may themselves be involved in the autoimmune process (27). In addition, complement and autoantibodies other than TRabs may play important roles in AITD (see below). GD and HT patients seem to have mixed Th1/Th2 cytokine profiles (31). Classically, Th2 cytokines are predominant in B cell-dominated autoimmunity, whereas Th1 cytokines are primarily produced in $\mathrm{T}$ cell-dependent diseases.

\section{The thyroid-associated antigens and autoantibodies in GD}

There are three major TAs: the thyroid-stimulating hormone (thyrotrophin) receptor (TSH-R), thyroglobulin ( $\mathrm{Tg}$ ) and thyroid peroxidase (TPO). The TAs are rather specific for the thyroid, although the TSH-R is expressed by fibroblasts in the dermis and the retrobulbar tissue as well (24). Tg is present in orbital tissue in patients with TAO, and is thought to be involved, albeit not directly, in the pathogenesis of TAO (32). The TSH$\mathrm{R}$ consists of two subunits (A and B). The extracellular A subunit is the target of TSH-R antibodies (23). A part of the A subunit may be shed to the circulation; in fact, the shedded, rather than the membrane attached, part of the A subunit, may be the primary target of TRabs (33).

The other prime autoantibodies in GD are TPO antibodies (TPOabs) and Tg antibodies (Tgabs), which are frequently present, but not a sine qua non as with TRabs. TPOabs and Tgabs can be detected in approximately $70 \%$ and $50 \%$ respectively of patients with GD (1). The thyroid autoantibodies are, however, not specific for thyroid autoimmunity (34) and, although being useful in clinical routine, a clear distinction between autoantibody positivity and negativity is of limited value in immunological terms since, for example, circulating Tgabs can be found in practically all individuals $(35,36)$. These antibodies belong to the so-called natural autoantibodies that are encoded by immunoglobulin (Ig)-variable genes in germ-line configuration and exhibit low-affinity binding to wellconserved epitopes of a broad variety of foreign and self antigens $(37,38)$. They exhibit a less restricted idiotype pattern than disease-associated antibodies (35). We have shown that natural Tgabs are instrumental in mediating the uptake and presentation of $\mathrm{Tg}$ by $\mathrm{B}$ cells, a mechanism that might be involved in maintaining peripheral tolerance to $\mathrm{Tg}$ (36). The fraction of Tg-responsive B cells and CD4 + T cells in a healthy individual can be raised considerably by increasing the Tgab concentration in the environment (39).

It is thus possible that the presence of Tgabs is not just an epiphenomenon to $\mathrm{T}$ cell-mediated thyroid tissue damage, but may in fact promote uptake and presentation of $\mathrm{Tg}$ by B cells and other APCs, thereby regulating $\mathrm{T}$ cell-effector mechanisms. An unidentified part of IgGs from sera of GD patients induce disruption of normal skin and orbital fibroblast function, resulting in $\mathrm{T}$ cell infiltration and hyaluronan synthesis, which may be particularly important in extrathyroidal manifestations of the disease. The underlying mechanism probably involves interaction with the insulin-like growth factor-I receptor (IGF-IR), which might act as a TA $(40-42)$.

The thyroid is the main production site of autoantibodies (23) but regional lymph nodes and bone marrow have been shown to contribute to the production (43). It is well accepted that thyroid autoantibodies may persist years after total thyroidectomy (44). Contributing factors to antibody persistence may be the shedding and circulation of the functionally antigenic part of the TSH-R A subunit (33), continued extrathyroidal production of autoantibodies and potential longevity of dedicated plasma cells (45).

\section{Thyroid immunohistopathology in GD: the thyroid as a lymphoid organ}

The lymphocytic infiltrate, seen in the thyroid in GD, consists mainly of T cells with approximately $9-15 \%$ of the total CD 45 + cells being B cells characterized by CD20 positivity $(46,47)$. The B cells are mainly scattered as single cells or appear in small groups in the T lymphocytic infiltrate (46). In a seminal work, Armengol et al. (48) found lymphocytic infiltrates containing germinal 
centres (GC) in 100\% (eight of eight) of HT and 54\% (14 of 26) of GD thyroids by careful routine histopathologic assessment, whereas only one in 22 patients with multinodular goiter had GCs (48). B cells were abundant in the GCs, and are believed to be of oligoclonal origin (48). Less vigorous routine assessment might disclose fewer GCs, whereas the most sensitive approach may be immunostaining for follicular DCs, thus exposing their reticular network in GCs.

Upon phenotyping of GD thyroid CD20 + B cells (thy-B), Segundo et al. (46) found two major populations: approximately two-thirds of $\mathrm{B}$ cells were of probable marginal zone derivation $(\operatorname{Ig} M+\operatorname{IgD}$ low to negative) and one-third were isotype-switched IgG + memory cells (46). Subsequent studies have shown that a third population is present in patients with GCs. This latter population is different from non-GC thy-B cells in a different Ig expression (47).

Armengol et al. (48) found evidence of Ig gene rearrangements in the lymphocytic infiltrates in GD and HT thyroids by RT-PCR examination of the recombinase-associated genes RAG-1 and RAG-2 involved in $\mathrm{V}(\mathrm{D}) \mathrm{J}$ gene rearrangements. The expression was higher than in other lymph nodes, tonsils and sometimes even the thymus (48). The Ig isotype switching (47) and V(D)J rearrangements (48) provide preliminary evidence of the thyroid with GCs being a fully functional secondary lymphoid organ conducting somatic hypermutation and affinity maturation. In GCs, memory B cells and plasma cells are formed (49). Indeed, Tg and TPO are shown to bind to B cells and plasma cells in the GCs of patients with AITD (48). Molecules involved in B and T lymphocyte compartmentalization and formation of GCs are expressed at high levels in the thyroids from AITD patients with thyroidal GCs $(26,47)$.

Ectopic secondary lymphoid follicles are reported in various autoimmune and inflammatory diseases (48), and are a feature of, for example, thyroid-associated pretibial myxoedema (25). Transfection of DCs to mice may induce de novo formation of pancreatic GCs containing follicular DCs and the initiation of insulindependent diabetes in mice (50). In human thyroids, follicular DCs are a hallmark of autoimmunity and GC formation (29). Regarding the importance of B cells in GCs, Takemura et al. (6), in a series of wellconducted experiments, showed that B cells were necessary for $\mathrm{CD} 4+\mathrm{T}$ cell function in human $\mathrm{RA}$ synovium implanted on severe combined immunodeficiency (SCID) mice. Furthermore, it is of particular interest that experimental $\mathrm{CD} 20+\mathrm{B}$ cell depletion in these mice abrogated GCs and diminished CD $3+$ and $\mathrm{CD} 4+\mathrm{T}$ cell infiltration as well as interferon- $\gamma$ and interleukin (IL)-1 $\beta$ production (6). TPOab levels and local Tgab production seems to be dependent upon intrathyroidal GCs $(47,48)$. Furthermore, the TRab levels may correlate with the presence of GCs in GD thyroids (48).

\section{Circulating B cells}

Patients with untreated GD have an increased number of circulating $\mathrm{B}$ cells, including $\mathrm{CD} 5+\mathrm{B}$ cells which are involved, for example, in the production of natural autoantibodies $(51,52)$. In euthyroid GD patients changes may be more subtle, although $\mathrm{CD} 5+\mathrm{B}$ cell expansion has been noted (46). Circulating autoreactive $\mathrm{IgG}+\mathrm{CD} 27+$ memory B cells are, however, frequently found in AITD patients, in contrast to that seen in normal subjects (49). Phenotyping of thy-B and peripheral blood B cells from the same subjects shows some differences: for example, CD5, IgD and IgM are mainly expressed on peripheral blood B cells, and $\operatorname{IgG}$ on thy-B (memory) cells (46). As for T cells, GD patients have increased CD4:CD8 ratios $(27,52)$.

\section{B/T cell interaction: the $B$ cell as an antigen- presenting cell}

A crucial role for B cells as APCs has been demonstrated in a number of murine models of autoimmune diseases $(5-10)$, and is suggested by the sometimes apparently autoantibody-independent effects of B cell depletion in clinical studies, as discussed later. In murine autoimmune thyroiditis, Braley-Mullen et al. (11) demonstrated the importance of B cells in the initiation of thyroiditis, in an autoantibody-independent manner. In a GD model, Pichurin et al. (12) showed that B cell-deficient mice were unable to elicit the normal $\mathrm{T}$ cell response to immunization with TSH-R. Conversely, the production of autoantibodies seems dependent on the help of CD4 + T cells (53). In a human in vitro system, we have demonstrated (36) that depletion of peripheral blood mononuclear cells for B cells markedly reduced $\mathrm{CD} 4+\mathrm{T}$ cell responses to $\mathrm{Tg}$ in healthy individuals, and that formation of complement-activating immune complexes between $\mathrm{Tg}$ and Tg-reactive natural antibodies promoted the response of Tg-reactive CD4 + T cells (36). Moreover, the presence of Tgabs from patients with HT further enhanced this $\mathrm{T}$ cell response (39). On the basis of these findings, we propose that autoantibodies and complement are instrumental in the uptake of autoantigen for presentation by B cells. B cells may further be involved in autoimmunity by virtue of their production of autoantibodies and their capability to produce regulatory cytokines, for example, IL-10 (54). Various surface antigens present on B cells may be involved in autoimmunity, for example, activation of B cells mediated by $\mathrm{B}$ cell-activating factor (BAFF) receptors may enhance plasmablast survival and thereby autoantibody secretion $(55,56)$.

Perhaps particularly important is the CD40/CD40L (CD154) system of $\mathrm{APC} / \mathrm{CD} 4+\mathrm{T}$ cell interaction. Upon CD40/CD40L engagement, B7-1 or B7-2 (CD80/CD86) molecules are activated on the APC cell 
membrane which, upon interaction with T cell CD28 or the cytotoxic T lymphocyte antigen-4 (CTLA-4) confers an increase or a decrease respectively in $\mathrm{T}$ cell function, for example, by the production of cytokines, CD4 + $\mathrm{CD} 25+$ regulatory $\mathrm{T}$ cells or by controlling Fasmediated apoptosis $(57,58)$. CTLA- 4 gene polymorphisms may be involved in the susceptibility to GD (20, 58). The importance of $\mathrm{B}$ cells in modulating $\mathrm{T}$ cell functions was shown in Takemura's RA synoviumSCID mouse chimeras, where decreases in T cell infiltration, GC size and inflammatory cytokines were seen upon B cell depletion (6). In humans, changes in $\mathrm{T}$ cell surface markers such as CD40L down-regulation and a decrease in $\mathrm{T}$ cell activation markers (CD69 and human leukocyte antigen-DR (HLA-DR)) follow $\mathrm{B}$ cell depletion in peripheral blood mononuclear cells of SLE patients (59). Moreover, normalization of T cell and macrophage infiltration of the bone marrow upon $\mathrm{B}$ cell depletion has been shown in a patient with pure red cell aplasia (60).

\section{Possible interactions between B cells and fibroblasts}

A central cell in the development of TAO seems to be the fibroblast (26). Orbital fibroblasts exposed to IgG from GD patients produce the $\mathrm{T}$ cell chemoattractants IL-16 and RANTES due to the presence of autoantibodies towards the IGF-IR $(40,41)$. Orbital fibroblasts from TAO patients proliferate when exposed to autologous T cells; a proliferation which is partly dependent upon CD40 on the fibroblasts interacting with $\mathrm{T}$ cell CD40L (61). The production of hyaluronan by orbital fibroblasts has been shown to be induced by autoantibody and CD40 stimulation $(42,62)$.

As described above, B cell depletion may cause qualitative and quantitative changes in local and circulating T cells $(6,59,60)$. As such, apart from a potential effect on autoantibodies, B cell depletion may affect aberrant fibroblast function indirectly through effects on T cells. Recently, fibroblasts from lung tissue were shown to express CD40L (63). At present it is not known whether $B$ cells and fibroblasts may interact directly through the CD40-CD40L pathway. Importantly, TAO fibroblasts exposed to RA IgG and vice versa show IGF-IRmediated production of the $\mathrm{T}$ cell chemoattractant IL16 (64). No such response was seen when the IgG or fibroblasts were derived from non-autoimmune subjects (64). Moreover, it is by now well recognized that synovial, like orbital, fibroblasts proliferate and produce inflammatory cytokines, when activated through the CD40-CD40L pathway $(26,65)$. Thus, a common pathogenetic pathway and potential common mechanisms of the action of B cell-depletion therapy in RA and TAO, based upon changes in fibroblast function, may exist. As reviewed later, clinical effect of B cell depletion is observed in RA (66).

\section{RTX, a B cell-depleting agent}

RTX (F. Hoffmann-La Roche Ltd., Basel, Switzerland) is a chimeric monoclonal antibody directed against CD20, a B cell-specific surface marker, which is expressed by pre-B cells and B cells, but not by stem cells or most plasma cells (Fig. $1 A$ and $B$ ) (67). CD20 is probably operating as a calcium channel, and may be involved in B cell maturation (68). No human ligand for CD20 has been identified, and

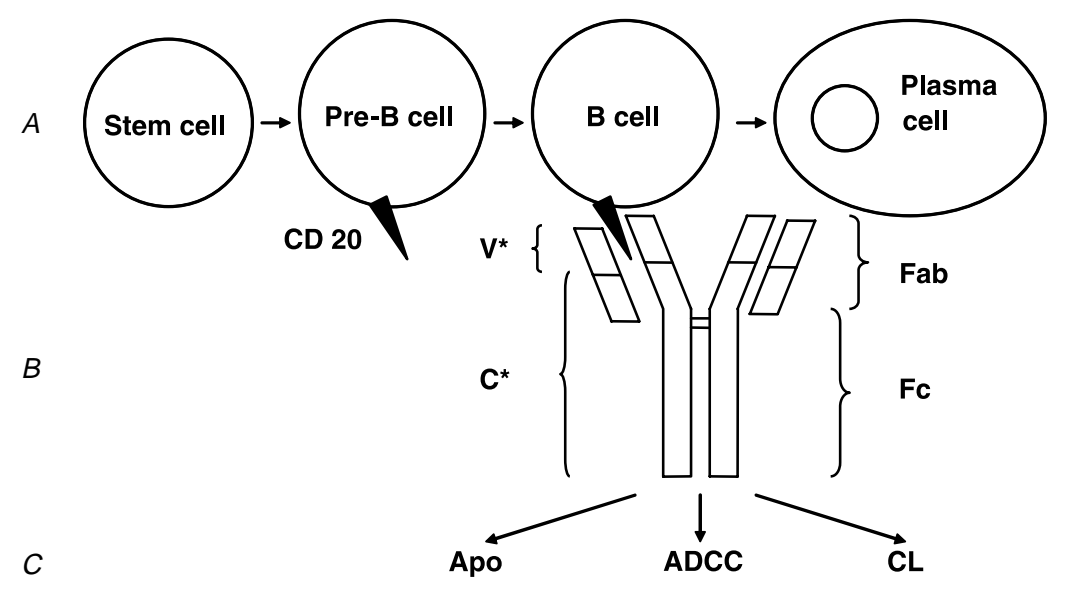

Figure 1 RTX: a monoclonal chimeric anti-CD20 antibody. $(A)$ The expression of the B cell-specific surface molecule CD20 (black triangular shapes) at different stages of $\mathrm{B}$ cell development. $(B)$ Murine variable heavy and light chain regions $\left(\mathrm{V}^{*}\right)$ are cloned onto human heavy and light chains forming the constant region $\left(C^{*}\right)$ of the chimeric $\lg G 1 \kappa$ monoclonal antibody RTX. The $V^{*}$ form a part of the antigen-binding region (Fab) recognizing CD20. The fully human Fc regions are responsible for effector mechanisms. (C) The effector mechanisms of RTX, resulting in B cell depletion, are apoptosis (Apo), antibody-dependent cellular cytotoxicity (ADCC) and complement-mediated lysis $(\mathrm{CL})$. 
CD20 knockout mice are viable without apparent physical or immunological abnormalities (68).

RTX has proved effective in the treatment of several haematological diseases, primarily non-Hodgkin's lymphomas, where it has been considered a state-of-the-art supplement to chemotherapy since its Federal Drug Administration (FDA) approval in 1997 (14). The mechanisms of action of RTX is depletion of CD20 + cells by antibody- and complement-dependent cytotoxicity as well as by induction of apoptosis (Fig. 1C) (69). RTX causes complete B cell depletion in a matter of days. Circulating B cells become detectable again after a median of 4-6 months in most diseases, normal levels being reached after approximately 9-12 months. In autoimmunity, longer depletion times may occur. T cell and NK cell counts are usually not affected. B cell depletion is reported in, for example, salivary glands, bone marrow and spleen $(70,71)$.

A standard lymphoma dose of RTX is four infusions of $375 \mathrm{mg} / \mathrm{m}^{2}$, given 1 week apart. This dose is used in most autoimmune disease trials, although lower doses or fewer infusions have also been used. Currently, the price of a full dose is approximately 10000 euros. More than 370000 patients have been treated with RTX (72). The reported use in autoimmune diseases is presently approaching 1000 patients, primarily with benign haematological diseases and RA. Increasing offlabel use of the drug, on a compassionate and experimental basis for various diseases, has been noted (73). The literature is rich in case reports, but there is only one placebo-controlled, randomized study in autoimmune diseases (66), and immunological characterization of treatment responses are scarce and just appearing. So far, there are no reports on anti-B cell therapy in AITD.

The most well-documented effects of RTX in autoimmunity are presented below. We focus on RA, SLE and immune thrombocytopenic purpura (ITP), and have chosen to present the largest studies with the most thorough immunological and toxicological evaluations. Other anti-CD20 agents conjugated to radioactive isotopes as, for example, ${ }^{131} \mathrm{I}$ are marketed (74), and a fully humanized, and thus potentially less immunogenic anti-CD20 antibody has been developed (75). Various other monoclonal antibodies aimed at B cells (for example, anti-CD22, anti-B cell receptor and anti$\mathrm{BAFF}$ ), as well as +molecules involved in $\mathrm{B} / \mathrm{T}$ cell interaction (for example, anti-CD4, anti-CD40L and anti-CTLA-4) may be other rational targets in autoimmune diseases (30, 57, 76). However, as substantial safety monitoring presently exists only for RTX, our focus is solely on this drug. The effects of B cell depletion in autoimmunity may theoretically be exerted on several levels, cellular as well as humoral (Table 1).

\section{RTX in the treatment of RA}

RA is generally considered a T cell-driven disease. However, as noted, B cells have been shown to be important
Table 1 Potential effector mechanisms of B cell-depleting therapy in autoimmune diseases.

Impairment of the B cell function as APCs, thereby providing less stimuli to, for example, CD4 + T-helper cell proliferation and cytokine production

Disruption of aberrant GC function, resulting in decreased production of disease-specific memory B cells, plasma cells and autoantibodies

Depletion of plasma cell precursors, thereby possibly mediating diminished autoantibody production and other changes in circulating Igs

Abrogation of a potentially vicious circle of self-perpetuating auto-reactive $\mathrm{B}$ cell clones, thereby providing a potentially permanent cure

Modulation of the behaviour of other immunoactive cells, e.g. fibroblasts, via potential changes in T cell functions and/or autoantibody levels

in the synovial reactions (6). The primary experience with RTX therapy in RA derives from the group of Edwards and Cambridge. The first results from 2001 in five patients (77) have now been extended in a major, randomized, double-blinded study involving 161 treatment-resistant rheumafactor-positive $(\mathrm{RF}+)$ RA patients (66). Using RTX in combination therapy with methotrexate (MTX) or cyclophosphamide (CTX), a persistent effect in down-scoring American College of Rheumatology (ACR) disease activity criteria by $50 \%$ (ACR50) was shown with ACR50 at 48 weeks being $35 \%$ and $27 \%$ respectively versus $5 \%$ on MTX monotherapy. RTX monotherapy resulted in ACR 50 in $15 \%$ of patients versus the $5 \%$ treated with the gold-standard MTX treatment (not significant) (66). Repeated RTX infusions may be necessary to maintain long-term responses. Advance reports show responses $(\mathrm{ACR} 20+)$ for up to 3 years in approximately $80 \%$ of $31 \mathrm{RF}+$ patients (78) on retreatment. B cell depletion per se is not the only mechanism of action since RF patients do not seem to have any effect from the treatment despite efficient B cell depletion (78).

\section{RTX in the treatment of SLE}

SLE is an autoimmune disease with a number of organ manifestations. Various autoantibodies are present in patients with SLE, anti-dsDNA, antinuclear antibodies and lupus anticoagulant being the most prominent. B cells are known to play an important role in SLE (79), and may exert antibody-independent effects (8) in addition to producing disease-associated antibodies. In 2002, a study in six patients showed promising results, on clinical and paraclinical parameters, of combination therapy (RTX and CTX) (80). A dose escalation study using RTX as monotherapy in 17 patients with SLE has subsequently demonstrated the efficacy of RTX in reducing disease activity in patients with successful B cell depletion (81). Tokunaga et al. (82) demonstrated an effect in five of five patients receiving RTX $\left(375 \mathrm{mg} / \mathrm{m}^{2}\right)$ for 2 weeks in addition to oral 
prednisolone. Two of these patients, with severe central nervous system (CNS) involvement, became fully alert in 2 and 5 days after starting treatment. Sfikakis and coworkers (59) demonstrated an effect of full dose RTX and oral prednisolone in eight of ten patients with lupus nephritis, five of whom achieved a complete response at 2-8 months post-treatment, and maintained this at 12 months (59). RTX may have a particularly beneficial effect on lupus nephritis, as confirmed by post-treatment renal biopsies $(81,83)$.

Recent studies have addressed flowcytometric changes post-RTX in SLE patients. One study (82) shows down-regulation of CD40 and CD80 involved in the $\mathrm{B} / \mathrm{T}$ cell interaction in the remaining $\mathrm{CD} 19+\mathrm{B}$ cells. Another study (59) showed a fourfold decrease in CD40L on CD4 $+\mathrm{T}$ cells as well as significant decreases in $\mathrm{T}$ cell activation markers (CD69 and HLA-DR) and NK cells, whereas overall T cell counts increased (59). Furthermore, depletion of an autoreactive subset of memory $\mathrm{B}$ cells (VH4.34 cells) is seen (84).

\section{RTX in the treatment of ITP}

Focusing on autoimmune diseases where the effects of RTX have been assessed, ITP may be the one with greatest resemblance to GD, at least as regards the importance of circulating antibodies. As with GD, ITP can be transferred foetomaternally and via plasma (85). Recently Cooper et al. (86) reported on 57 patients with chronic ITP (platelet counts (pc) below $\left.30 \times 10^{9} / \mathrm{l}\right)$ receiving standard $4 \times$ RTX therapy. The overall response rate was $54 \%$, with complete response $\left(\mathrm{pc}>150 \times 10^{9} / \mathrm{l}\right)$ in $32 \%$ and partial response in $23 \%$ (86). Remarkably, 16 of the 18 complete response patients remained in remission after a median of 73 (range: 24-165) weeks post-treatment, often despite long-lasting complete B cell repopulation. Standard salvage therapy (Ig and/or prednisolone) was allowed when low pcs occurred (12 patients), but did not seem to be involved in the lasting responses. Spontaneous remission may be seen in ITP. These patients had, however, received a median of three (range: $2-8$ ) previous treatment attempts, with splenectomy performed in 31 patients $(54 \%)$, rendering it likely that the cure rate was related to RTX treatment. The efficacy data are in keeping with the literature review by Zaja et al. (87) involving 73 patients and our own experience (88).

\section{The influence of RTX on Igs, antibacterial antibodies and autoantibodies}

Generally, Ig levels are well maintained upon treatment with RTX. IgM is most affected, although values below the normal range are uncommon after one treatment. Retreatment with RTX, on the other hand, may induce substantial decreases in IgM levels $(66,78,81)$.
Antibacterial antibody levels are reported to be maintained $(66,81)$ even during RTX retreatment $(78)$.

In $\mathrm{RA}$, a rapid fall in specific antibody (as compared with general Ig levels) levels is observed (66). The efficiency of autoantibody depletion in SLE varies somewhat more, with a clinical effect being seen despite persistent autoantibody levels (84). We speculate that the pathogenesis of ITP and GD may be similar, due to the presence of circulating pathogenetic autoantibodies. Data on the influence of RTX on antibody levels in ITP are, however, variable and rarely reported. One reason for this may be difficulties in testing for the heterogeneous anti-platelet antibodies (85).

The experience in autoimmune disorders shows different timing of clinical responses to treatment, pointing to potential differences in pathogenesis and effector mechanisms (Table 1). Responses may be almost immediate (for example, the autoantibody response in RA and clinical improvement in CNS complications in SLE) or delayed by months (for example, the clinical response in SLE and RA). Indeed, in ITP, a biphasic response pattern is seen $(86,88)$. In general, the temporal relationship between disease activity and autoantibody levels deserves further elucidation. As regards the immunological effects, the knowledge of the influence of RTX on B cell and T cell behaviour and cytokine production is particularly limited.

\section{Adverse effects of RTX treatment}

Infusion-related adverse effects are common, but they are benign and self-limiting $(66,86)$. Most often hyperthermia, hypotension or nausea is seen. Serious infusion-related reactions have not been reported in autoimmunity, and are rare in haematological malignancies $(14,72)$. B cell depletion is accompanied by remarkably few adverse effects associated with infections, since the Ig and antibacterial antibody levels are maintained. In the RA study, serious infections occurred in $2.5 \%$ in the control group (one patient) as opposed to $3.3 \%$ in the RTX groups (four patients). An increased occurrence of pulmonary infections may be seen on repeated treatment (78). In 57 ITP patients, no serious infections or increases in minor infections were noted, although a large number of the subjects had been splenectomized (86). In a retrospective study of 35 patients with ITP, two patients with severe chronic obstructive lung disease died, one of respiratory insufficiency, one of pneumonia. Both deaths were thought to be unrelated to the treatment (88). A review of the adverse effect profile in haematological malignancies, where major knowledge has been gathered, supports the notion that RTX therapy is safe (72). Even treatment twice a year for 2 years is tolerable without a significantly increased rate of infections (89). Cases of vasculitis, epidermolysis, joint symptoms, reactivation of vira leading to, for example, hepatitis B and other rare phenomena are reported 
upon treatment with RTX in a registered frequency of less than 1 in 1000 patients (Rituximab product information 07/03/05, http://www.emea.eu.int/ humandocs/Humans/EPAR/mabthera/mabthera.htm). In autoimmunity, however, for example, serum sickness and neutropenia may be encountered at much higher frequencies than are registered (73). With regard to post-RTX thyroid function, little is known. One RA patient is reported to have developed a goitre, not further specified, post-RTX (90). Two anti-CD20 antibodies conjugated to radioactive isotopes are FDA approved. One of these is conjugated to ${ }^{131} \mathrm{I}$ and may result in hypothyroidism due to direct toxicity, whereas this is apparently not the case for the other compound (74). Overall, RTX is considered to be a safe agent, even in the setting of non-malignant diseases (72).

\section{Relevance of RTX for treatment of GD}

B cell depletion by means of RTX therapy has been proved effective in a large fraction of patients with treatment-resistant autoimmune diseases, including RA (66), SLE $(59,81,82)$ and ITP (86-88). In addition to being precursor cells for the Ig (and autoantibody)secreting plasma cells, B cells are also known as critical APCs in AITD $(9,10,36,39)$ and other autoimmune diseases $(5-8)$, a role which may be partly dependent upon complement and autoantibodies as shown for Tgabs $(36,39)$.

In AITD, the thyroid gland may house secondary lymphoid organs containing GC-conducting affinity maturation and somatic hypermutation (48). As such, GCs are involved in the formation of specific B memory cells, plasma cells and thyroid autoantibodies $(47,48)$. Targeting intrathyroidal B cells may disrupt GCs and thereby the production of high-affinity thyroid autoantibodies $(47,48)$, and perhaps decrease the stimulation of self-reactive $\mathrm{CD} 4+\mathrm{T}$ cells and the production of proinflammatory cytokines (6).

$B$ cell depletion could prove efficient in the treatment of both HT and GD. In HT, a direct effect on B cells in the lymphocyte-infiltrated thyroid could be expected. However, the majority of HT patients have atrophic thyroiditis - dominated by fibrosis - at diagnosis. Recent reports suggest histological normalization after RTX treatment in renal glomeruli and salivary glands (71, $81,83)$, leaving open the question of reversibility in HT. However, the ease of treatment with levothyroxine questions whether RTX therapy in HT is worthwhile or cost effective.

In this report we have focused on GD, an archetypical autoantibody-dependent autoimmune disease in which disruption of autoantibody production would be the ultimate target for therapy. It is possible that temporary disruption of unbalanced B cell homeostasis, depletion of memory B cells and depletion of precursors of the autoantibody-producing plasma cells could have a beneficial, or even curative, effect in GD. The pathogenesis of the extrathyroidal manifestations of GD, in particular TAO, is murkier than thyroidal GD and may be more T cell dominated; antibodies are, however, involved in the pathogenesis $(41,42)$. Apart from the potential effect of RTX on the function of the B cell as an APC and on autoantibody production, we have hypothesized that B cell depletion may have a beneficial effect, directly or through the influence on T cells, on disturbed fibroblast function in TAO (Table 1). Of interest, considering the clinical effect of RTX in RA, synovial fibroblasts from RA patients and orbital fibroblasts from TAO patients seem to share activation pathways $(26,64)$.

TAO may be a debilitating complication to GD both physically and psychologically, and at present treatment responses in some patients with severe TAO is unsatisfactory. For such patients, B cell-depleting agents may become a relevant and even cost-effective supplement to existing treatment options (91). Lasting 6-12 months, B cell depletion using RTX may have the advantage of a long-lasting or perhaps definitive effect compared with previous treatment attempts aimed at clearing antibodies (for example, plasmapheresis).

Other agents modulating $\mathrm{B}$ or $\mathrm{T}$ cell behaviour, or anti-cytokine agents, have not been reviewed here. When assessing the feasibility of a novel treatment for a benign disease, security issues are of utmost importance. RTX has been approved for clinical use since 1997. So far, 370000 patients have been treated with RTX, and almost a decade of follow-up renders some notion of RTX safety. De novo autoimmune manifestations are rare, as are, somewhat surprisingly, postRTX infections. All in all, RTX therapy is considered safe and with an acceptable profile of adverse advents, even in a setting of patients with non-malignant diseases (72). Given the potential benefits of $B$ cell depletion in GD, studies of RTX treatment of patients with severe refractory GD, in particular patients with TAO, seem warranted.

\section{Acknowledgements}

This work was supported by the Agnes and Knut Mørk Foundation and the Novo Nordisk Foundation.

\section{References}

1 Weetman AP. Graves' disease. New England Journal of Medicine 2000343 1236-1248.

2 Cooper DS. Antithyroid drugs. New England Journal of Medicine $2005352905-917$.

3 Åsman P. Ophthalmological evaluation in thyroid-associated ophthalmopathy. Acta Ophthalmologica Scandinavia 200381 $437-448$.

4 Roberts CG \& Ladenson PW. Hypothyroidism. Lancet 2004363 $793-803$.

5 Serreze DV \& Silveira PA. The role of B lymphocytes as key antigen-presenting cells in the development of T cell-mediated autoimmune type 1 diabetes. Current Directions in Autoimmunity $20036212-227$. 
6 Takemura S, Klimiuk PA, Braun A, Goronzy JJ \& Weyand CM. $\mathrm{T}$ cell activation in rheumatoid synovium is B cell dependent. Journal of Immunology $2001 \mathbf{1 6 7} 4710-4718$.

7 Chan OT, Madaio MP \& Shlomchik MJ. B cells are required for lupus nephritis in the polygenic, Fas-intact MRL model of systemic autoimmunity. Journal of Immunology $19991633592-3596$.

8 Chan OT, Hannum LG, Haberman AM, Madaio MP \& Shlomchik MJ. A novel mouse with B cells but lacking serum antibody reveals an antibody-independent role for B cells in murine lupus. Journal of Experimental Medicine 1999189 $1639-1648$

9 Hutchings P, Rayner DC, Champion BR, Marshall-Clarke S, Macatonia S, Roitt I \& Cooke A. High efficiency antigen presentation by thyroglobulin-primed murine splenic B cells. European Journal of Immunology 198717 393-398.

10 Guo J, Wang Y, Rapoport B \& McLachlan SM. Evidence for antigen presentation to sensitized $\mathrm{T}$ cells by thyroid peroxidase (TPO)specific $\mathrm{B}$ cells in mice injected with fibroblasts co-expressing TPO and MHC class II. Clinical and Experimental Immunology $200011938-46$.

11 Braley-Mullen H \& Yu S. Early requirement for B cells for development of spontaneous autoimmune thyroiditis in NOD.H-2h4 mice. Journal of Immunology 2000165 7262-7269.

12 Pichurin P, Aliesky H, Chen CR, Nagayama Y, Rapoport B \& McLachlan SM. Thyrotrophin receptor-specific memory T cell responses require normal $\mathrm{B}$ cells in a murine model of Graves' disease. Clinical and Experimental Immunology 2003134 396-402.

13 Maloney DG, Liles TM, Czerwinski DK, Waldichuk C, Rosenberg J, Grillo-Lopez A \& Levy R. Phase I clinical trial using escalating single-dose infusion of chimeric anti-CD20 monoclonal antibody (IDEC-C2B8) in patients with recurrent B-cell lymphoma. Blood $1994842457-2466$.

14 Boye J, Elter T \& Engert A. An overview of the current clinical use of the anti-CD20 monoclonal antibody rituximab. Annals of Oncology $200314520-535$.

15 Edwards JC, Cambridge G \& Abrahams VM. Do self-perpetuating B lymphocytes drive human autoimmune disease? Immunology $199997188-196$.

16 Hasselbalch HC. B-cell depletion with rituximab - a targeted therapy for Graves' disease and autoimmune thyroiditis. Immunology Letters $2003 \mathbf{8 8} 85-86$.

17 Brix TH, Kyvik KO, Christensen K \& Hegedus L. Evidence for a major role of heredity in Graves' disease: a population-based study of two Danish twin cohorts. Journal of Clinical Endocrinology and Metabolism 200186 930-934.

18 Brix TH, Hansen PS, Kyvik KO \& Hegedus L. Aggregation of thyroid autoantibodies in first-degree relatives of patients with autoimmune thyroid disease is mainly due to genes: a twin study. Clinical Endocrinology $200460329-334$.

19 Brix TH \& Hegedus L. Environmental factors in the pathogenesis of Graves' disease. In Graves' Orbital Disease, pp 127-138. Eds JJ Dutton \& B Haik. New York: Marcel Dekker, 2002.

20 Tomer Y \& Davies TF. Searching for the autoimmune thyroid disease susceptibility genes: from gene mapping to gene function. Endocrine Reviews $2003 \mathbf{2 4} 694-717$.

21 Volpe R. The immunoregulatory disturbance in autoimmune thyroid disease. Autoimmunity 19882 55-72.

22 Adams DD \& Purves HD. Abnormal responses in the assay of thyrotrophin. Proceedings of the University of Otago Medical School $19563411-12$.

23 Rapoport B \& McLachlan SM. Thyroid autoimmunity. Journal of Clinical Investigation $2001 \mathbf{1 0 8} 1253-1259$.

24 Prabhakar BS, Bahn RS \& Smith TJ. Current perspective on the pathogenesis of Graves' disease and ophthalmopathy. Endocrine Reviews $200324802-835$.

25 Rapoport B, Alsabeh R, Aftergood D \& McLachlan SM. Elephantiasic pretibial myxedema: insight into and a hypothesis regarding the pathogenesis of the extrathyroidal manifestations of Graves' disease. Thyroid 200010 685-692.
26 Smith TJ. Insights into the role of fibroblasts in human autoimmunediseases. Clinical and Experimental Immunology $2005 \mathbf{1 4 1}$ 388-397.

27 Weetman AP. Cellular immune responses in autoimmune thyroid disease. Clinical Endocrinology 200461 405-413.

28 Solerte SB, Precerutti S, Gazzaruso C, Locatelli E, Zamboni M, Schifino N, Bonacasa R, Rondanelli M, Taccani D, Ferrari E \& Fioravanti M. Defect of a subpopulation of natural killer immune cells in Graves' disease and Hashimoto's thyroiditis: normalizing effect of dehydroepiandrosterone sulfate. European Journal of Endocrinolology 2005152 703-712.

29 Kabel PJ, Voorbij HA, De Haan M, van der Gaag RD \& Drexhage HA. Intrathyroidal dendritic cells. Journal of Clinical Endocrinology and Metabolism 198866 199-207.

30 Vasu C, Holterman MJ \& Prabhakar BS. Modulation of dendritic cell function and cytokine production to prevent thyroid autoimmunity. Autoimmunity 200336 389-396.

31 Ajjan RA \& Weetman AP. Cytokines in thyroid autoimmunity. Autoimmunity 200336 351-359.

32 Marino M, Chiovato L, Lisi S, Altea MA, Marcocci C \& Pinchera A. Role of thyroglobulin in the pathogenesis of Graves' ophthalmopathy: the hypothesis of Kriss revisited. Journal of Endocrinological Investigation 200427 230-236.

33 Chen CR, Pichurin P, Nagayama Y, Latrofa F, Rapoport B \& McLachlan SM. The thyrotropin receptor autoantigen in Graves disease is the culprit as well as the victim. Journal of Clinical Investigation $20031111897-1904$.

34 Jensen E, Hyltoft PP, Blaabjerg O, Hansen PS, Brix TH, Kyvik KO \& Hegedus L. Establishment of a serum thyroid stimulating hormone (TSH) reference interval in healthy adults, The importance of environmental factors, including thyroid antibodies. Clinical Chemistry and Laboratory Medicine 2004 42 824-832.

35 Hurez V, Dietrich G, Kaveri SV \& Kazatchkine MD. Polyreactivity is a property of natural and disease-associated human autoantibodies. Scandinavian Journal of Immunology 199338 190-196.

36 Nielsen CH, Leslie RG, Jepsen BS, Kazatchkine MD, Kaveri SV \& Fischer E. Natural autoantibodies and complement promote the uptake of a self antigen, human thyroglobulin, by B cells and the proliferation of thyroglobulin-reactive CD4(+) T cells in healthy individuals. European Journal of Immunology 200131 2660-2668.

37 Dighiero G, Guilbert B \& Avrameas S. Naturally occurring antibodies against nine common antigens in humans sera. II. High incidence of monoclonal Ig exhibiting antibody activity against actin and tubulin and sharing antibody specificities with natural antibodies. Journal of Immunology 1982128 2788-2792.

38 Avrameas S. Natural autoantibodies: from 'horror autotoxicus' to 'gnothi seauton'. Immunology Today 199112 154-159.

39 Nielsen CH, Hegedus L \& Leslie RG. Autoantibodies in autoimmune thyroid disease promote immune complex formation with self antigens and increase B cell and CD4 + T cell proliferation in response to self antigens. European Journal of Immunology $200434263-272$.

40 Pritchard J, Horst N, Cruikshank W \& Smith TJ. Igs from patients with Graves' disease induce the expression of T cell chemoattractants in their fibroblasts. Journal of Immunology $2002 \mathbf{1 6 8}$ 942-950.

41 Pritchard J, Han R, Horst N, Cruikshank WW \& Smith TJ. Immunoglobulin activation of $\mathrm{T}$ cell chemoattractant expression in fibroblasts from patients with Graves' disease is mediated through the insulin-like growth factor I receptor pathway. Journal of Immunology $20031706348-6354$.

42 Smith TJ \& Hoa N. Immunoglobulins from patients with Graves' disease induce hyaluronan synthesis in their orbital fibroblasts through the self-antigen, insulin-like growth factor-I receptor. Journal of Clinical Endocrinology and Metabolism 200489 5076-5080.

43 Weetman AP, McGregor AM, Wheeler MH \& Hall R. Extrathyroidal sites of autoantibody synthesis in Graves' disease. Clinical and Experimental Immunology 198456 330-336. 
44 Chiovato L, Latrofa F, Braverman LE, Pacini F, Capezzone M, Masserini L, Grasso L \& Pinchera A. Disappearance of humoral thyroid autoimmunity after complete removal of thyroid antigens. Annals of Internal Medicine 2003139 346-351.

45 Slifka MK \& Ahmed R. Long-lived plasma cells: a mechanism for maintaining persistent antibody production. Current Opinion in Immunology $1998 \mathbf{1 0} 252-258$.

46 Segundo C, Rodriguez C, Garcia-Poley A, Aguilar M, Gavilan I, Bellas C \& Brieva JA. Thyroid-infiltrating B lymphocytes in Graves' disease are related to marginal zone and memory B cell compartments. Thyroid 200111 525-530.

47 Segundo C, Rodriguez C, Aguilar M, Garcia-Poley A, Gavilan I, Bellas C \& Brieva JA. Differences in thyroid-infiltrating B lymphocytes in patients with Graves' disease: relationship to autoantibody detection. Thyroid $200414337-344$.

48 Armengol MP, Juan M, Lucas-Martin A, Fernandez-Figueras MT, Jaraquemada D, Gallart T \& Pujol-Borrell R. Thyroid autoimmune disease: demonstration of thyroid antigen-specific $\mathrm{B}$ cells and recombination-activating gene expression in chemokine-containing active intrathyroidal germinal centers. American Journal of Pathology $2001159861-873$.

49 Leyendeckers H, Voth E, Schicha H, Hunzelmann N, Banga P \& Schmitz J. Frequent detection of thyroid peroxidase-specific IgG + memory B cells in blood of patients with autoimmune thyroid disease. European Journal of Immunology $2002 \mathbf{3 2}$ 3126-3132.

50 Ludewig B, Odermatt B, Landmann S, Hengartner H \& Zinkernagel RM. Dendritic cells induce autoimmune diabetes and maintain disease via de novo formation of local lymphoid tissue. Journal of Experimental Medicine 1998188 1493-1501.

51 Iwatani Y, Amino N, Kaneda T, Ichihara K, Tamaki H, Tachi J, Matsuzuka F, Fukata S, Kuma K \& Miyai K. Marked increase of CD5 + B cells in hyperthyroid Graves' disease. Clinical and Experimental Immunology 198978 196-200.

52 Bossowski A, Urban M \& Stasiak-Barmuta A. Analysis of changes in the percentage of B (CD19) and T (CD3) lymphocytes, subsets CD4, CD8 and their memory (CD45RO), and naive (CD45RA) T cells in children with immune and non-immune thyroid diseases. Journal of Pediatric Immunology and Metabolism 200316 63-70.

53 Macht LM, Corrall RJ, Banga JP \& Elson CJ. Control of human thyroid autoantibody production in SCID mice. Clinical and Experimental Immunology 199391 390-396.

54 Fillatreau S, Sweenie CH, McGeachy MJ, Gray D \& Anderton SM. B cells regulate autoimmunity by provision of IL-10. Nature Immunology $20023944-950$.

55 Avery DT, Kalled SL, Ellyard JI, Ambrose C, Bixler SA, Thien M, Brink R, Mackay F, Hodgkin PD \& Tangye SG. BAFF selectively enhances the survival of plasmablasts generated from human memory B cells. Journal of Clinical Investigation 2003112 286-297.

56 Tuscano JM, Harris GS \& Tedder TF. B lymphocytes contribute to autoimmune disease pathogenesis: current trends and clinical implications. Autoimmunity Reviews 20032 101-108.

57 Goodnow CC. Pathways for self-tolerance and the treatment of autoimmune diseases. Lancet 2001357 2115-2121.

58 Weetman AP. Autoimmune thyroid disease: propagation and progression. European Journal of Endocrinolology 2003148 1-9.

59 Sfikakis PP, Boletis JN, Lionaki S, Vigklis V, Fragiadaki KG, Iniotaki A \& Moutsopoulos HM. Remission of proliferative lupus nephritis following $B$ cell depletion therapy is preceded by down-regulation of the $\mathrm{T}$ cell costimulatory molecule CD40 ligand: an open-label trial. Arthritis and Rheumatism $2005 \mathbf{5 2}$ $501-513$

60 Oyaizu N, Kozai Y, Kodo H, Sunaga S, Iwabuchi K, Higashihara M \& Mori S. A case of pure red cell aplasia complicated with diffuse large B cell lymphoma, T-cell-rich/histiocyte-rich variant: effectiveness of rituximab and implications for a common immunopathogenic role of B lymphocytes. Acta Haematologica 2005113 194-197.
61 Feldon SE, Park DJ, O'loughlin CW, Nguyen VT, LandskronerEiger S, Chang D, Thatcher TH \& Phipps RP. Autologous T-lymphocytes stimulate proliferation of orbital fibroblasts derived from patients with Graves' ophthalmopathy. Investigative Ophthalmology and Visual Science 200546 3913-3921.

62 Cao HJ, Wang HS, Zhang Y, Lin HY, Phipps RP \& Smith TJ. Activation of human orbital fibroblasts through CD40 engagement results in a dramatic induction of hyaluronan synthesis and prostaglandin endoperoxide $\mathrm{H}$ synthase- 2 expression. Insights into potential pathogenic mechanisms of thyroid-associated ophthalmopathy. Journal of Biological Chemistry $1998 \quad 273$ 29615-29625.

63 Kaufman J, Sime PJ \& Phipps RP. Expression of CD154 (CD40 ligand) by human lung fibroblasts: differential regulation by IFN-gamma and IL13, and implications for fibrosis. Journal of Immunology $20041721862-1871$.

64 Pritchard J, Tsui S, Horst N, Cruikshank WW \& Smith TJ. Synovial fibroblasts from patients with rheumatoid arthritis, like fibroblasts from Graves' disease, express high levels of IL-16 when treated with Igs against insulin-like growth factor-1 receptor. Journal of Immunology 2004173 3564-3569.

65 Yellin MJ, Winikoff S, Fortune SM, Baum D, Crow MK, Lederman S \& Chess L. Ligation of CD40 on fibroblasts induces CD54 (ICAM1) and CD106 (VCAM-1) up-regulation and IL-6 production and proliferation. Journal of Leukocyte Biology $1995 \mathbf{5 8} 209-216$.

66 Edwards JC, Szczepanski L, Szechinski J, Filipowicz-Sosnowska A, Emery P, Close DR, Stevens RM \& Shaw T. Efficacy of B-celltargeted therapy with rituximab in patients with rheumatoid arthritis. New England Journal of Medicine $20043 \mathbf{3 0 0} 2572$-2581.

67 Reff ME, Carner K, Chambers KS, Chinn PC, Leonard JE, Raab R, Newman RA, Hanna N \& Anderson DR. Depletion of B cells in vivo by a chimeric mouse human monoclonal antibody to CD20. Blood $199483435-445$.

68 Cragg MS, Walshe CA, Ivanov AO \& Glennie MJ. The biology of $\mathrm{CD} 20$ and its potential as a target for mAb therapy. Current Directions in Autoimmunity 20058 140-174.

69 Smith MR. Rituximab (monoclonal anti-CD20 antibody): mechanisms of action and resistance. Oncogene 200322 7359-7368.

70 Kneitz C, Wilhelm M \& Tony HP. Effective B cell depletion with rituximab in the treatment of autoimmune diseases. Immunobiology $2002206519-527$.

71 Pijpe J, Van Imhoff GW, Vissink A, Van der Wal JE, Kluin PM, Spijkervet FK, Kallenberg CG \& Bootsma H. Changes in salivary gland immunohistology and function after rituximab monotherapy in a patient with Sjogren's syndrome and associated MALT-lymphoma. Annals of the Rheumatic Diseases $20056 \mathbf{6}$ 958-960.

72 Mohrbacher A. B cell non-Hodgkin's lymphoma: rituximab safety experience. Arthritis Research and Therapy 20057 S19-S25.

73 Gottenberg JE, Guillevin L, Lambotte O, Combe B, Allanore Y, Cantagrel A, Larroche C, Soubrier M, Bouillet L, Dougados M, Fain O, Farge D, Kyndt X, Lortholary O, Masson C, Moura B, Remy P, Thomas T, Wendling D, Anaya JM, Sibilia J \& Mariette $\mathrm{X}$. Tolerance and short term efficacy of rituximab in 43 patients with systemic autoimmune diseases. Annals of the Rheumatic Diseases $200564913-920$.

74 Bischof DA. The role of nuclear medicine in the treatment of nonHodgkin's lymphoma (NHL). Leukemia and Lymphoma $2003 \mathbf{4 4}$ S29-S36.

75 Tahir H, Rohrer J, Bhatia A, Wegener WA \& Isenberg DA. Humanized anti-CD20 monoclonal antibody in the treatment of severe resistant systemic lupus erythematosus in a patient with antibodies against rituximab. Rheumatology $2005 \mathbf{4 4} 561-562$.

76 Looney RJ, Anolik J \& Sanz I. B cells as therapeutic targets for rheumatic diseases. Current Opinion in Rheumatology 200416 $180-185$.

77 Edwards JC \& Cambridge G. Sustained improvement in rheumatoid arthritis following a protocol designed to deplete B lymphocytes. Rheumatology 200140 205-211. 
78 Edwards JC \& Leandro MJ. Repeated B-cell depletion with rituximab in rheumatoid arthritis. Arthritis Research and Therapy 20035 S42.

79 Chan OT, Madaio MP \& Shlomchik MJ. B cells are required for lupus nephritis in the polygenic, Fas-intact MRL model of systemic autoimmunity. Journal of Immunology $19991633592-3596$.

80 Leandro MJ, Edwards JC, Cambridge G, Ehrenstein MR \& Isenberg DA. An open study of B lymphocyte depletion in systemic lupus erythematosus. Arthritis and Rheumatism $2002 \mathbf{4 6}$ $2673-2677$.

81 Looney RJ, Anolik JH, Campbell D, Felgar RE, Young F, Arend LJ, Sloand JA, Rosenblatt J \& Sanz I. B cell depletion as a novel treatment for systemic lupus erythematosus: a phase I/II dose-escalation trial of rituximab. Arthritis and Rheumatism $2004 \mathbf{5 0}$ 2580-2589.

82 Tokunaga M, Fujii K, Saito K, Nakayamada S, Tsujimura S, Nawata M \& Tanaka Y. Down-regulation of CD40 and CD80 on $\mathrm{B}$ cells in patients with life-threatening systemic lupus erythematosus after successful treatment with rituximab. Rheumatology $200544176-182$.

83 Van Vollenhoven RF, Gunnarsson I, Welin-Henriksson E, Sundelin B, Osterborg A, Jacobson SH \& Klareskog L. Biopsyverified response of severe lupus nephritis to treatment with rituximab (anti-CD20 monoclonal antibody) plus cyclophosphamide after biopsy-documented failure to respond to cyclophosphamide alone. Scandinavian Journal of Rheumatology 200433 423-427.

84 Anolik JH, Barnard J, Cappione A, Pugh-Bernard AE, Felgar RE Looney RJ \& Sanz I. Rituximab improves peripheral B cell abnormalities in human systemic lupus erythematosus. Arthritis and Rheumatism $2004 \mathbf{5 0} 3580-3590$.

85 Cines DB \& Blanchette VS. Immune thrombocytopenic purpura New England Journal of Medicine 2002346 995-1008.

86 Cooper N, Stasi R, Cunningham-Rundles S, Feuerstein MA Leonard JP, Amadori S \& Bussel JB. The efficacy and safety of
B-cell depletion with anti-CD20 monoclonal antibody in adults with chronic immune thrombocytopenic purpura. British Journal of Haematology $2004125232-239$.

87 Zaja F, Vianelli N, Sperotto A, de Vita S, Iacona I, Zaccaria A, Masolini P, Tomadini V, Tani M, Molinari AL, Baccarani M \& Fanin R. B-cell compartment as the selective target for the treatment of immune thrombocytopenias. Haematologica $2003 \mathbf{8 8}$ 538-546.

88 Braendstrup P, Bjerrum OW, Nielsen OJ, Jensen BA, Clausen NT, Hansen PB, Andersen I, Schmidt K, Andersen TM, Peterslund NA, Birgens HS, Plesner T, Pedersen BB \& Hasselbalch HC. Rituximab chimeric anti-CD20 monoclonal antibody treatment for adult refractory idiopathic thrombocytopenic purpura. American Journal of Hematology $2005 \mathbf{7 8} 275-280$.

89 Hainsworth JD, Litchy S, Shaffer DW, Lackey VL, Grimaldi M \& Greco FA. Maximizing therapeutic benefit of rituximab: maintenance therapy versus re-treatment at progression in patients with indolent non-Hodgkin's lymphoma - a randomized phase II trial of the Minnie Pearl Cancer Research Network. Journal of Clinical Oncology 200523 1088-1095.

90 Szczepanski L, Szechinski J, Filipowicz-Sosnowska A, Emery P, Edwards JCW, Magrini F, Lehane PB \& Shaw T. Safety data from 48 weeks follow-up of a randomised controlled trial of rituximab in patients with rheumatoid arthritis. Arthritis and Rheumatism $2003 \mathbf{4 8}$ S121.

91 El Fassi D, Nielsen CH, Hasselbalch HC \& Hegedus L. Successful B lymphocyte depletion with Rituximab in a patient with recurrent Graves' disease and severe ophthalmopathy. Thyroid 200515 S28.

Received 18 August 2005

Accepted 16 December 2005 